\title{
Role of the $\mathrm{NH}_{2}$-terminal Membrane Spanning Domain of Multidrug Resistance Protein 1/ABCC1 in Protein Processing and Trafficking ${ }^{D}$
}

\author{
Christopher J. Westlake, ${ }^{* \dagger}$ Susan P.C. Cole, ${ }^{\ddagger \ddagger}$ and Roger G. Deeley ${ }^{\dagger \ddagger}$
}

\begin{abstract}
Departments of *Biochemistry and $\ddagger$ Pathology and Molecular Medicine and ${ }^{\dagger}$ Cancer Research Institute, Queen's University, Kingston, Ontario, Canada K7L 3N6
\end{abstract}

Submitted December 23, 2004; Revised March 1, 2005; Accepted March 2, 2005

Monitoring Editor: Jean Gruenberg

\begin{abstract}
Multidrug resistance protein (MRP)1/ABCC1 transports organic anionic conjugates and confers resistance to cytotoxic xenobiotics. In addition to two membrane spanning domains (MSDs) typical of most ATP-binding cassette (ABC) transporters, MRP1 has a third MSD (MSD0) of unknown function. Unlike some topologically similar ABCC proteins, removal of MSD0 has minimal effect on function, nor does it prevent MRP1 from trafficking to basolateral membranes in polarized cells. However, we find that independent of cell type, the truncated protein accumulates in early/recycling endosomes. Using a real-time internalization assay, we demonstrate that MSD0 is important for MRP1 retention in, or recycling to, the plasma membrane. We also show that MSD0 traffics independently to the cell surface and promotes membrane localization of the core-region of MRP1 when the two protein fragments are coexpressed. Finally, we demonstrate that MSD0 becomes essential for trafficking of MRP1 when the COOH-terminal region of the protein is mutated. These studies demonstrate that MSD0 and the COOH-terminal region contain redundant trafficking signals, which only become essential when one or the other region is missing or is mutated. These data explain apparent differences in the trafficking requirement for MSD0 and the COOH-terminal region of MRP1 compared with other ABCC proteins.
\end{abstract}

\section{INTRODUCTION}

Multidrug resistance protein (MRP) $1 / \mathrm{ABCC} 1$ is a member of the " $\mathrm{C}$ " branch of the ATP-binding cassette (ABC) superfamily. When overexpressed in various cell types, MRP1 confers resistance to structurally diverse natural product cytotoxins, as well a certain heavy metal oxyanions and antimetabolites (Deeley and Cole, 2003). The protein also has been detected in tumors derived from many different cell types and may be an important factor in the failure of chemotherapy in treating some forms of cancer (Bates, 2003). Many potential physiological and exogenous substrates of MRP1 are organic anion conjugates with glutathione (GSH), glucuronate, or sulfate (Deeley and Cole, 2003). In addition, the protein is capable of ATP-dependent, GSH-stimulated transport of various unconjugated hydrophobic substrates (Loe et al., 1996, 1997; Renes et al., 1999), as well as certain

This article was published online ahead of print in $M B C$ in Press (http://www.molbiolcell.org/cgi/doi/10.1091/mbc.E04-12-1113) on March 16, 2005.

$\square$ The online version of this article contains supplemental material at MBC Online (http:/ / www.molbiolcell.org).

Address correspondence to: Roger G. Deeley (deeleyr@post. queensu.ca).

Abbreviations used: ABC, ATP-binding cassette; CL, cytoplasmic loop; CFP, cyan fluorescent protein; ER, endoplasmic reticulum; HEK, human embryonic kidney; HRP, horseradish peroxidase; $\mathrm{LTC}_{4}$, leukotriene $\mathrm{C}_{4}$; MDCK, Madin-Darby canine kidney; MRP, multidrug resistance protein; MSD, membrane-spanning domain; SUR, sulfonylurea receptor; $\mathrm{TB}$, transport buffer; TM, transmembrane; YFP, yellow fluorescent protein. glucuronate and sulfate conjugates (Sakamoto et al., 1999; Leslie et al., 2001; Qian et al., 2001b).

ABC proteins typically consist of two tandemly arranged polytopic membrane spanning domains (MSDs) and two cytoplasmic nucleotide binding domains (NBDs) (Higgins, 2001). In addition to the four "core" domains, MRP1 and certain other ABCC proteins contain a third, $\mathrm{NH}_{2}$-terminal MSD (MSD0) (Deeley and Cole, 2003). Human ABCC proteins with comparable $\mathrm{NH}_{2}$-terminal MSDs include the MRP1 homologues MRP2/ABCC2, MRP3/ABCC3, MRP6/ ABCC6, and MRP7/ABCC10, as well as the sulfonylurea receptors SUR1A/ABCC8 and SUR2A,B/ABCC9 (Tusnady et al., 1997; Haimeur et al., 2004). Despite relatively low sequence similarity, experimental evidence and predictive hydrophobicity determinations suggest that in general, the $\mathrm{NH}_{2}$-terminal extensions of these proteins contain five transmembranes (TMs) and have an extracellular $\mathrm{NH}_{2}$ terminus (Hipfner et al., 1997; Kast and Gros, 1997; Tusnady et al., 1997; Raab-Graham et al., 1999). A similar third MSD also is present in the yeast ABCC protein cadmium factor Ycf1, a probable ortholog of MRP1 (Li et al., 1996), and in other ABCC proteins identified in plants and lower eukaryotes (Tusnady et al., 1997).

In MRP1, MSD0 is connected to the remainder of the protein by a cytoplasmic loop, CL3, of $\sim 108$ amino acids (Westlake et al., 2003). The cytoplasmic $\mathrm{NH}_{2}$ termini of ABCC proteins lacking MSD0 show some conservation of sequence with the start of CL3 in proteins such as MRP1, suggesting that the additional MSD may have been acquired by fusion of a gene encoding a core ancestral ABCC protein with one or more genes encoding other integral membrane proteins (Grant et al., 1997). Presently, a functional role for the $\mathrm{NH}_{2}$-terminal MSD has been best characterized in stud- 
ies of SUR1, where an interaction between MSD0 and the potassium channel, Kir6.2 is required for $\mathrm{K}_{\mathrm{ATP}}$-channel plasma membrane trafficking and gating (Otonkoski et al., 1999; Babenko and Bryan, 2003; Chan et al., 2003). In addition, the $\mathrm{NH}_{2}$-terminal MSDs of MRP2 and the yeast MRP1 orthologue, Ycf1, are necessary for apical membrane and vacuolar localization, respectively (Fernandez et al., 2002; Mason and Michaelis, 2002).

The function of MRP1 MSD0 is unknown. In contrast to SUR1A, MRP2, and Ycf1, MRP1 lacking MSD0 (MRP1 $204-1531)$ can traffic to the basolateral membrane in polarized cells and transport at least some substrates relatively efficiently (Bakos et al., 1998; Westlake et al., 2003). However, further truncation to remove as few as six amino acids from CL3 markedly decreases transport activity in insect cells and the protein is retained in the endoplasmic reticulum (ER) of mammalian cells (Westlake et al., 2003). $\mathrm{NH}_{2}$-terminal truncation of MRP1 to Ala ${ }^{213}$ in CL3 severely disrupts substrate binding and transport even in insect cells (Westlake et al., 2003). Thus, although the integrity of the cytoplasmic loop immediately after MSD0 is essential for protein processing and activity, it has been concluded that MSD0 is dispensable, at least with respect to trafficking and transport of some substrates. Nevertheless, certain point mutations or deletions in MSD0 decrease or eliminate MRP1 transport activity (Gao et al., 1998; Leslie et al., 2003; Ito et al., 2003) and a recent study of hybrid proteins in which TM1-3 of MSD0 were switched between MRP1 and MRP2 concluded that this $\mathrm{NH}_{2}$-terminal region influenced the kinetics of leukotriene $\mathrm{C}_{4}\left(\mathrm{LTC}_{4}\right)$ and methotrexate transport by the two homologues (Konno et al., 2003).

To further define the role of MSD0, we have used several approaches to examine its influence on the subcellular localization of MRP1 in both polarized and nonpolarized cells. These studies revealed that although MSD0-less MRP1 was able to traffic to the plasma membrane, the proportion of the protein in intracellular membrane compartments increased so that in transfected cells, $\sim 55 \%$ of MSD0-less MRP1 was not in the plasma membrane. Colocalization and real time internalization studies indicated that the intracellular protein was predominantly in early/recycling endosomes. Furthermore, plasma membrane localization of MSD0-less MRP1 could be restored by coexpression with MSD0. Although MSD0 is not absolutely required for plasma membrane trafficking of the core of the wild-type protein, we found that it became essential when the $\mathrm{COOH}$-terminal region of MRP1 was truncated or mutated. Consistent with a specific requirement for MSD0 of MRP1, neither of the $\mathrm{NH}_{2}$-terminal domains of the homologous MRP2 nor MRP3 rescued trafficking of a $\mathrm{COOH}$-terminally truncated protein, although in the presence of an intact $\mathrm{COOH}$-terminal region, the hybrid proteins trafficked normally. Thus, MSD0 and the $\mathrm{COOH}$-terminal region of MRP1 contains redundant trafficking/processing signals that explain why, unlike related ABCC proteins, elimination of either the $\mathrm{NH}_{2}-$ or $\mathrm{COOH}-$ terminal region alone fails to prevent targeting of MRP1 to the plasma membrane.

\section{MATERIALS AND METHODS}

\section{Materials}

$\left[14,15,19,20-{ }^{3} \mathrm{H}_{4}\right] \mathrm{LTC}_{4}\left(182 \mathrm{Ci} \mathrm{mmol}^{-1}\right)$ was purchased from PerkinElmer Life and Analytical Sciences (Boston, MA). LTC 4 was obtained from CalBiochem (San Diego, CA). Monoclonal antibodies (mAbs) MRPr1 and MRPm6 were obtained from Alexis (San Diego, CA). Fluorescent-conjugated secondary antibodies Alexa594-labeled transferrin and $\mathrm{NBD} \mathrm{\textrm {C } _ { 6 }}$-ceramide were purchased from Molecular Probes (Eugene, OR).

\section{Generation of MRP1 Variants}

MRP1 expression vectors encoding proteins lacking the first 203 amino acid residues or with mutated/chimeric $\mathrm{COOH}$-terminal regions have been described previously (Grant et al., 1994; Gao et al., 1996; Oian et al., 2001a; Westlake et al., 2003, 2004). Vectors for proteins that contained both modified $\mathrm{NH}_{2-}$ and $\mathrm{COOH}$-terminal regions were generated by ligation of mutant MRP1 fragments from the above-mentioned vectors into an appropriate recipient vector. A pcDNA 3.1(-) vector (Invitrogen, Burlington, Ontario, Canada) expressing MRP1 MSD0 (MRP1 $\left.1_{1-203}\right)$ was created by PCR by using the forward T7 vector backbone oligonucleotide and the reverse primer $5^{\prime}$-TCTGGTACCCTAGTGGATGGTTTCCGAGAACAGG-3' that resulted in addition of an Ala codon, a stop codon, and a KpnI site (underlined) following the codon for $\mathrm{His}^{203}$. COOH-terminal yellow fluorescent protein- (YFP) and cyan fluorescent protein (CFP)-tagged wild-type MRP1, MRP1 $1_{204-1531}$ and $\mathrm{MRP}_{1-203} \mathrm{cDNA}$ constructs (with termination codons eliminated by PCR) were generated by insertion into the multicloning sites of pEYFP-N1 and pECFP-N1 vectors (BD Biosciences Clontech, Palo Alto, CA). The pBudCE4.1 dual-expression vector (Invitrogen) was used to coexpress MRP1 MSD0 with the MRP1 core constructs.

Expression vectors for hybrid MRP1 proteins containing MSD0 from MRP2 and MRP3 were generated by ligating appropriate recombinant PCR products with the cDNA for $\mathrm{MRP}_{204-1531}$ and $M R P 1_{204-1501}$. Briefly, the coding sequence for the $\mathrm{NH}_{2}$-terminal 187 amino acids of MRP2 and 201 amino acids of MRP3 were amplified from previously described full-length cDNA (Ito et al., 2001a; Zhang et al., 2003) by using the reverse recombinant primers 5'-ATTAGGGTCGTGATTTTCTGAAAATCGTG-3' (MRP1 nt 617-607 underlined) and 5'-GGATTAGGGTCGACATTCTTTGCGGAGAAAAATGG-3' (MRP1 nt 610-620 underlined), respectively, and the forward T7 primer. These DNA products were annealed to the respective recombinant MRP1 fragments generated with the forward primers 5'-TTTCAGAAAATCAC GACCCTAATCCCTGC-3' (MRP2 nt 561-545, MRP1 nt 607-623 underlined) and 5'-GCAAAGAATGTCGACCCTAATCCCTGCCC-3' (MRP1 nt 610-626 and MRP3 nt 603-580) and a reverse primer downstream of unique BamHI site in MRP1. Chimeric constructs were assembled into pcDNA 3.1(-) or pCEBV7 vectors for expression in mammalian cells. In all cases, the fidelity of the constructs was confirmed by sequence analysis.

\section{Tissue Culture and Transfection}

MDCK-I, HepG2, HeLa, NIH-3T3, LLC-PK1, and HEK293 cells were cultured in DMEM in $10 \%$ fetal bovine serum. Transfections were performed using FuGENE6 (Roche Diagnostics, Laval, QC, Canada) according to the manufacturer's instructions. LLC-PK1 medium was supplement with F12 (Sigma Diagnostics Canada, Oakville, Ontario, Canada). Stable cells were generated by selection with Geneticin $(800 \mu \mathrm{g} / \mathrm{ml})$ or zeocine $(400 \mu \mathrm{g} / \mathrm{ml})$ for $10-14 \mathrm{~d}$. Clonal cell lines were produced by cell dilution and maintained in antibiotic supplemented medium.

\section{Immunocytochemistry and Transferrin Internalization Assays}

MDCK-I cells were grown on polycarbonate filters and glass coverslips. All other transient and stable transfectants were grown on glass coverslips coated with $0.1 \%$ gelatin. For subcellular localization studies, cells were fixed with $95 \%$ ice-cold ethanol, with the exception that $2 \%$ paraformaldehyde and digitonin $(25 \mu \mathrm{g} / \mathrm{ml})$ were used with certain antibodies, as described previously (Westlake et al., 2003). Cells were incubated with previously characterized MRP1 mAbs (with the exception of MRP1 variants fused to CFP and YFP), with and without $\mathrm{mAb}$ anti-calnexin (Sigma Diagnostics Canada), polyclonal antibody (pAb) TGN46, or mAb Lamp-2 (H4B4) (Santa Cruz Biotechnology, Santa Cruz, CA). Protein-antibody interactions were detected with Alexa fluorescent-conjugated secondary antibodies (Alexa488, Alexa546, and Alexa594). In some cases, fixed cells were stained with $\mathrm{NBD} \mathrm{C}_{6}$-ceramide at $4^{\circ} \mathrm{C}$ according to the manufacturer's instructions. Fluorophores were excited with a Leica TCS SP2 dual photon confocal microscope. For consistency, MRP1 is pseudocolored green, because MRP1 mAbs were detected with both green and red wavelength-excitable secondary antibodies, whereas CFP and YFP fusion proteins are pseudocolored blue and green, respectively.

For transferrin internalization assays, stable human embryonic kidney (HEK) 293 transfectants were grown to $>90 \%$ confluence on $0.17-m m$ Delta T dishes (Bioptechs, Butler, PA) and washed three times with DMEM, followed by incubation with and without Alexa594-labeled transferrin $(5 \mu \mathrm{g} / \mu \mathrm{l})$ for 0 , $5,10,15$, and $60 \mathrm{~min}$. Cells were excited by confocal microscopy on a heated stage at $37^{\circ} \mathrm{C}$ as described above. The colocalization observed between MRP1 fragments and with Alexa594-labeled transferrin exceeding a set fluorescence threshold was pseudocolored white in merged images by using ImageJ.

\section{Sucrose Density Gradient Membrane Fractionation}

HEK293 transfectants were disrupted by nitrogen cavitation (200 psi) in transport buffer (TB) (50 mM Tris, $250 \mathrm{mM}$ sucrose, $\mathrm{pH} 7.4$ ), and membranes were separated from nuclei and unbroken cells (Loe et al., 1996). The concentration of sucrose present in the isolated membranes was adjusted to $1.4 \mathrm{M}$, and a step density gradient was prepared in Beckman thin-wall tubes by 
using the adjusted membrane homogenate and $0.8,1.2,1.6,1.8$, and $2.0 \mathrm{M}$ sucrose. Membranes were centrifuged at $100,000 \times g$ for $2.5 \mathrm{~h}$ at $4^{\circ} \mathrm{C}$. Fractions were collected from the $0.8-1.2,1.2-1.4$, and 1.4-1.6 $\mathrm{M}$ sucrose interfaces; diluted in $10 \mathrm{mM}$ Tris, $25 \mathrm{mM}$ sucrose, $\mathrm{pH} 7.4$; and respun. Isolated membranes were diluted in TB, centrifuged at 100,000 $\times g$, and the resulting pellets were resuspended in TB by using a 27.5-gauge needle. Protein concentrations were determined by Bradford assay (Bio-Rad, Hercules, CA).

\section{N-Glycosidase F (PNGasF) Treatment of MRP1 Variants}

Crude membranes were prepared from HEK293 cells as described previously (Grant et al., 1994). Membranes (11 $\mu \mathrm{g})$ were incubated in denaturation buffer for $10 \mathrm{~min}$ at $37^{\circ} \mathrm{C}$, followed by addition of PNGaseF or control buffer according to the manufacturer's (New England Biolabs, Beverly, MA) instructions and incubated for $24 \mathrm{~h}$ at $37^{\circ} \mathrm{C}$. Proteins were diluted in $2 \times$ Laemmli buffer containing $100 \mathrm{mM}$ dithiothreitol.

\section{Immunoblotting}

Membrane proteins were resolved by 7.5\% SDS-PAGE and immunoblotted as described previously (Gao et al., 1996). MRP1 variants were detected with either mAb MRPr1, mAb QCRL-1, or mAb MRPm6. $\mathrm{Na}^{+} / \mathrm{K}^{+}$-ATPase was detected with a pAb raised in sheep (abcam.com). Horseradish peroxidase (HRP)-conjugated secondary antibodies and enhanced chemiluminescence techniques were used to detect antibody-protein interactions. The relative expression levels of MRP1 fragments observed were determined by densitometry of exposed films.

\section{RESULTS}

Subcellular Localization of Transiently Expressed WildType MRP1 and MRP1 $1_{204-1531}$ in Polarized and Nonpolarized Cells

Comparison of stably transfected polarized MDCK-I cells expressing either full-length or truncated protein $\left(M R P 1_{204-1531}\right)$ by immunofluorescence confocal microscopy suggested that a greater proportion of the MSD0-less construct was present intracellularly rather than on the plasma membrane (Figure 1A). To determine whether this change in subcellular distribution occurred in other polarized and nonpolarized cell lines, we compared the distribution of $M R P 1_{204-1531}$ with that of the full-length protein after transient transfection into HepG2 (Figure 1B), LLC-PK1 (Figure 1C), HeLa (Figure 1D), and NIH-3T3 (Figure 1E) cells. In contrast to intact MRP1, a substantial fraction of the truncated protein was detected in intracellular membranes in all cell lines, suggesting that either trafficking to, or retention in, the plasma membrane was compromised by the lack of MSD0 regardless of cell type.

\section{Comparison of the Subcellular Localization of Wild-Type} MRP1 and MRP1 $1_{204-1531}$ in Stably Expressing HEK293 Cells

To eliminate the possibility that the altered distribution of MRP $1_{204-1531}$ was a consequence of transient transfection, we isolated stably transfected HEK-MRP1 $1_{204-1531}$ cells that expressed levels of the truncated protein comparable (Supplementary Data Figure 1A) with those in previously characterized wild-type HEK-MRP1 transfectants (Grant et al., 1994). Immunofluorescence studies using the MRP1 mAbs QCRL-3 (Figure 2A) and MRPr1 (Figure 3, B, D, and F) confirmed that although $\mathrm{MRP}_{204-1531}$ could be detected in the plasma membrane, a significant amount of the protein was present in intracellular vesicular-like structures that was not apparent in cells expressing wild-type MRP1 (Figure 2A)

\section{Sucrose Density Fractionation of Cellular Membranes}

To obtain a more quantitative estimate of the distribution of wild-type MRP1 and MRP1 $1_{204-1531}$, cell membranes were fractionated by sucrose density gradient centrifugation. Total cell membranes from HEK293 cells expressing comparable levels of full-length protein or $M R P 1_{204-1531}$ were separated on a five-step, discontinuous sucrose gradient. The 1.2,
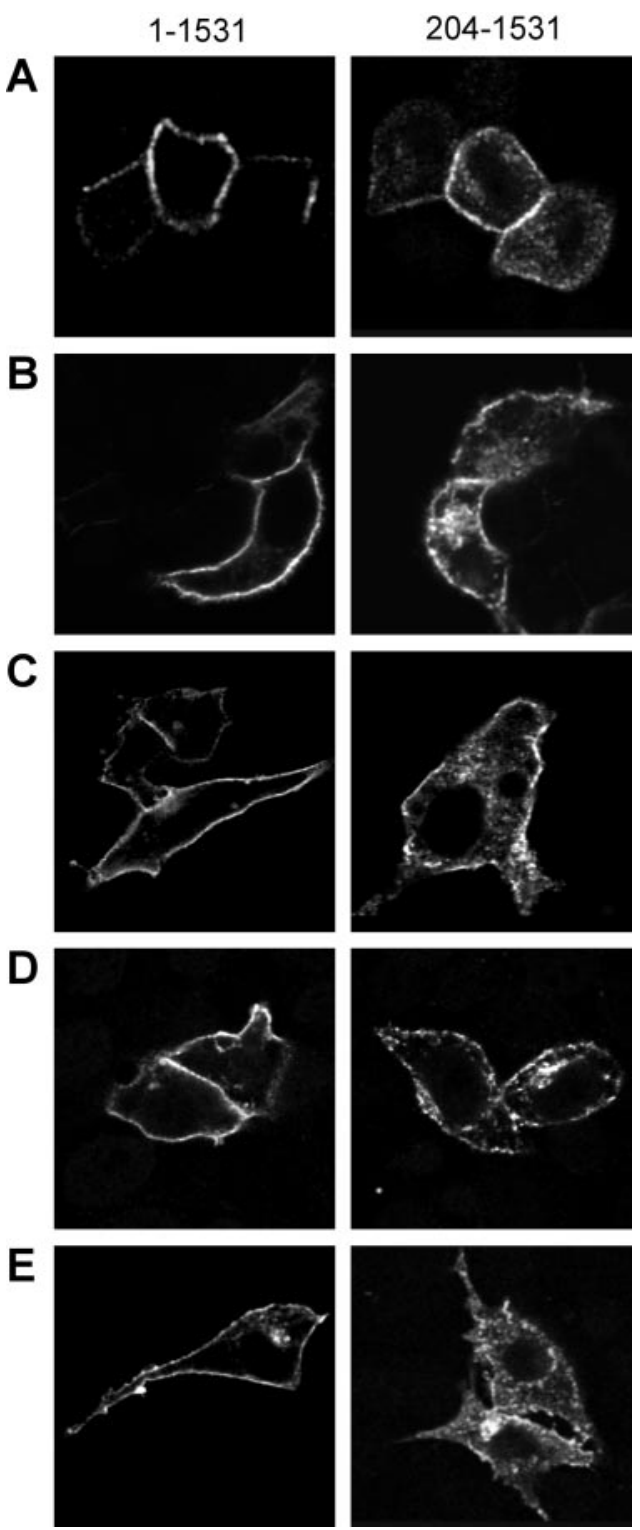

Figure 1. Comparison of the trafficking of wild-type and $\mathrm{MRP}_{204-153}$ transiently expressed in polarized and nonpolarized cell lines. Wildtype MRP1 (1-1531) (left) and MRP1 $1_{204-1531}$ (204-1531) (right) were transiently transfected into MDCK-I (A), HepG2 (B), LLC-PK1 (C), HeLa (D), and NIH-3T3 (E) mammalian cell lines. Four days after transfection, cells were fixed with ethanol and immunodetected with mAb MRPr1 and Alexa594 goat anti-rat and fluorescence observed as described in Materials and Methods.

1.4 , and $1.6 \mathrm{M}$ fractions were then recovered and analyzed by SDS-PAGE, followed by immunoblotting with the MRP1specific mAb MRPr1 and a pAb for the endogenous $\mathrm{Na}^{+} /$ $\mathrm{K}^{+}$-ATPase that served as a marker for the plasma membrane. Densitometry indicated that intact MRP1 and the $\mathrm{Na}^{+} / \mathrm{K}^{+}$-ATPase had a similar density distribution with $\sim 80 \%$ of the protein being recovered in the $1.2 \mathrm{M}$ sucrose fraction (Figure 2B). In support of the confocal studies indicating that a higher proportion of $M R P 1_{204-1531}$ is present in a nonplasma membrane compartment, only $\sim 45 \%$ of the truncated protein was present in the $1.2 \mathrm{M}$ fraction, with a similar amount being recovered in the $1.4 \mathrm{M}$ fraction (Figure 2B). 
A
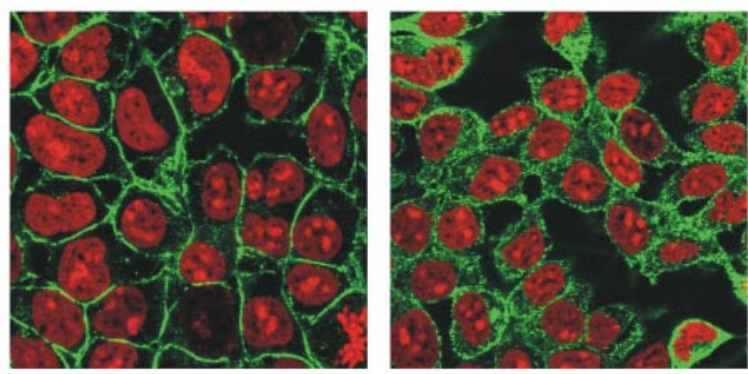

B

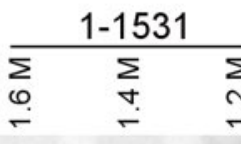

$\mathrm{Na}^{+} / \mathrm{K}^{+}$-ATPase

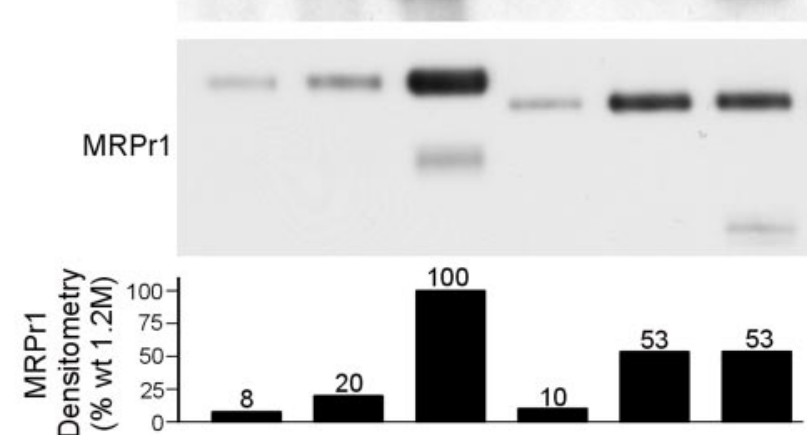

C
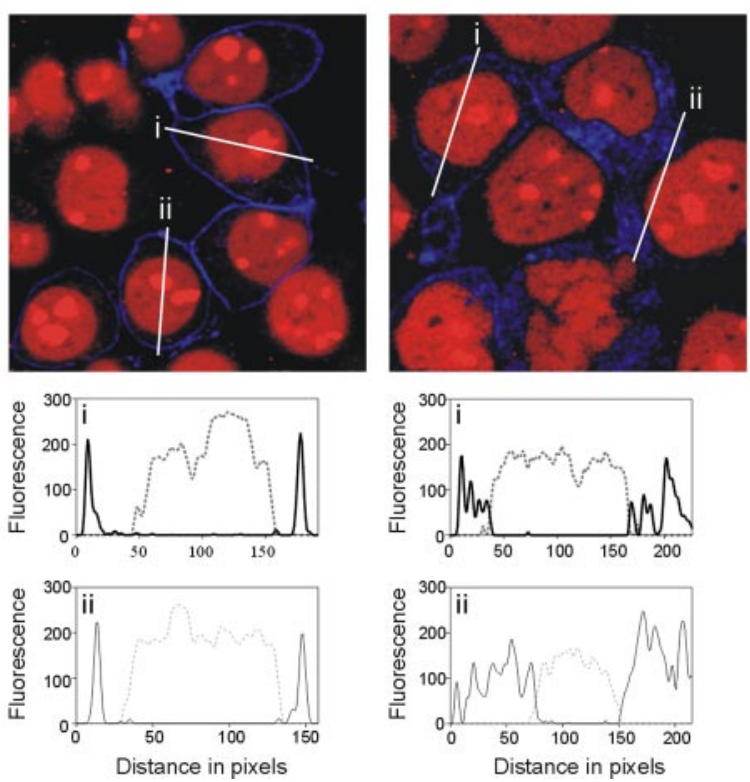

Figure 2. Localization and subcellular membrane distribution of MSD0-less MRP1 in HEK293 cells. (A) MRP1 (left) and MRP1 ${ }_{204-1531}$ (right) were immunodetected with $\mathrm{mAb}$ QCRL-3 and Alexa488 goat anti-mouse secondary antibodies (green signal) in paraformaldehyde-fixed stably expressing HEK293 cells. (B) Immunoblots of HEK-MRP1 and HEK-MRP1 $1_{204-1531}$ membranes ( $1 \mu \mathrm{g} /$ lane) fractionated on $0.8-2.0 \mathrm{M}$ nonlinear sucrose gradients, probed with $\mathrm{pAb}$ $\mathrm{Na}^{+} / \mathrm{K}^{+}$-ATPase and HRP-conjugated goat anti-chicken (top blot) and $\mathrm{mAb}$ MRPr1 and HRP-conjugated goat anti-rat (lower blot). The relative amount of chemiluminescent signal for the MRP1 pro-
A

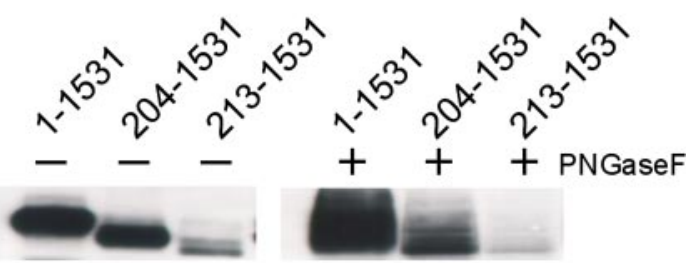

B

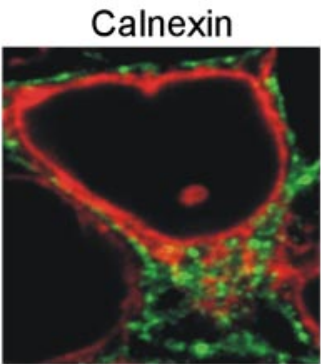

C Calnexin

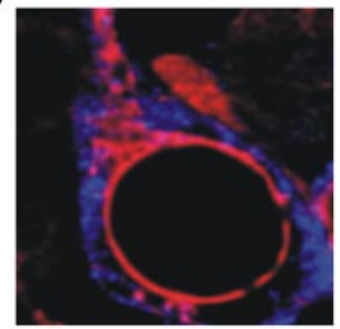

D

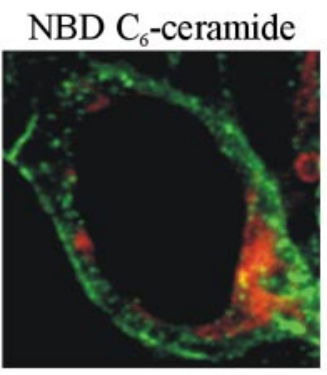

E

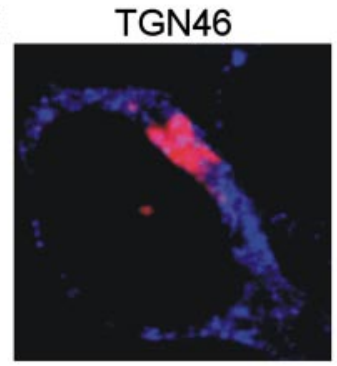

$\mathbf{F}$

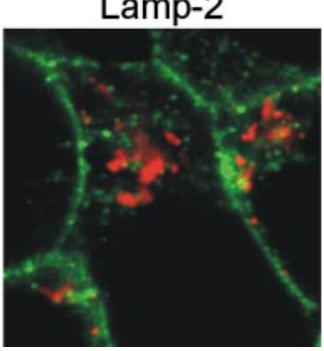

G

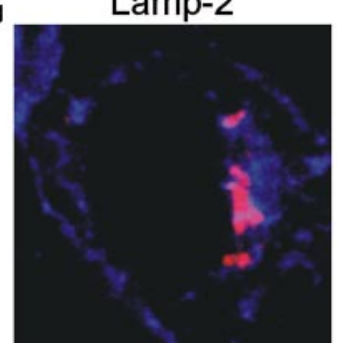

Figure 3. Processing and analysis of subcellular localization of $\mathrm{MRP}_{204-1531}$. (A) Immunoblot of full-length and variant MRP1 proteins in HEK293 total cellular membranes $(5 \mu \mathrm{g})$ incubated with and without PNGasF and probed with $\mathrm{mAb}$ QCRL-1 as described in Materials and Methods. MRP1 $1_{204-1531}(\mathrm{~B}, \mathrm{D}$, and $\mathrm{F})$ and $\mathrm{MRP}_{204-1531^{-}}$ CFP (C, E, and G) stably expressed in HEK293 cells were fixed with ethanol and incubated with the mAb anti-calnexin and Alexa546 goat anti-rabbit $\left(\mathrm{B}, \mathrm{C}\right.$, and red signal), or $\mathrm{NBD} \mathrm{C}_{6}$-ceramide $(\mathrm{D}$, red signal), or anti-TGN46 and Alexa594 goat anti-sheep (E, red signal), or the lysosomal marker Lamp-2 and Alexa546 goat anti-mouse (F,G, red signal) as described in Materials and Methods. Untagged MSD0-less MRP1 was detected with MRP1r1 and Alexa488 or Alexa594 goat anti-rat (green signals).

Figure 2. (cont) teins was determined by densitometry and plotted as a percentage of the wild-type in the $1.2 \mathrm{M}$ fraction. Based on these estimates the total level of expression of $\mathrm{MRP}_{204-1531}$ was $\sim 90 \%$ that of full-length MRP1. (C) MRP1 (left) and MRP1 $1_{204-1531}$ (right) were $\mathrm{COOH}$-terminal fused with CFP (blue signal) and stably expressed in HEK293 cells. Nuclei were counterstained with propidium iodide (red signal). Typical line fluorescence profiles of CFP-fusion proteins (solid line) and stained nuclei (dashed line) are plotted across individual cells ( $\mathrm{i}$ and ii). 


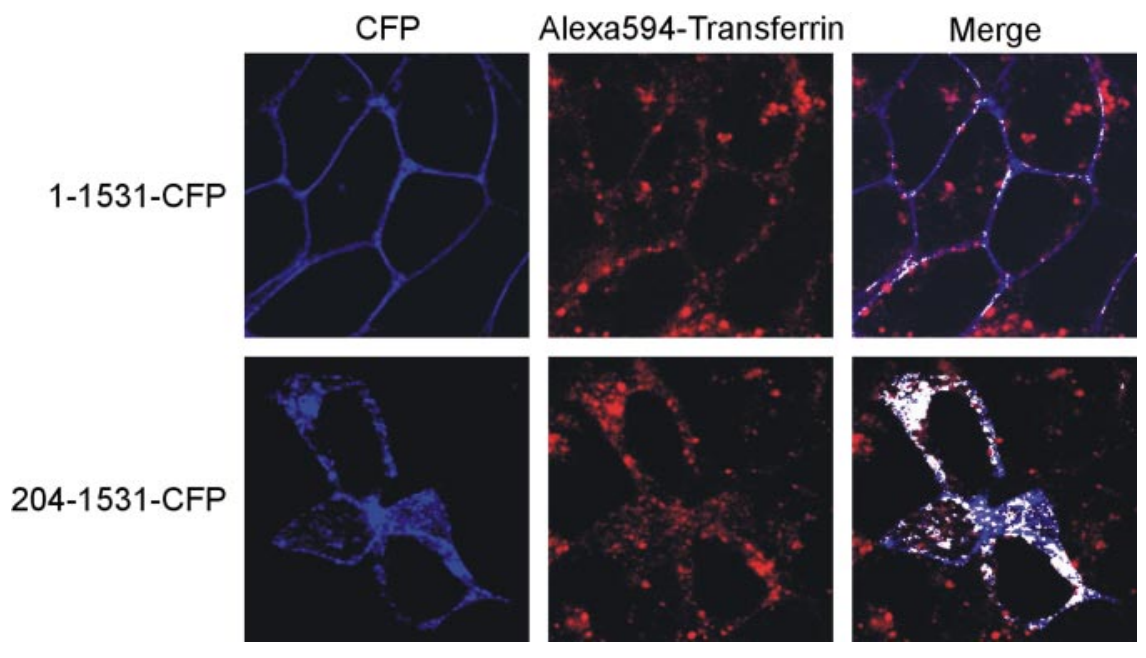

Figure 4. Colocalization of internalized Alexa594-labeled transferrin in vesicles expressing MRP1-CFP (1-1531-CFP) or MRP1 ${ }_{204-1531^{-}}$ CFP (204-1531-CFP) fusion proteins. Accumulation of Alexa594-labeled transferrin $(5 \mu \mathrm{g} / \mathrm{ml})$ after $30 \mathrm{~min}$ at $37^{\circ} \mathrm{C}$ in HEK-MRP1-CFP and HEK-MRP1 $1_{204-1531^{-}}$ CFP cells was determined as described in Materials and Methods. Vesicles in which Alexa594-labeled transferrin (red signal) and the CFP fusion proteins (blue signal) colocalized have been pseudocolored white in the merged images.

\section{MRP1 $1_{204-1531}-$ CFP Subcellular Localization}

We also examined the subcellular localization of intact MRP1 and $\mathrm{MRP}_{204-1531}$ fused at their $\mathrm{COOH}$ termini to CFP and stably expressed in HEK293 cells. As reported previously for MRP1 with a COOH-terminal GFP tag (Ito et al., 2001b; Haimeur et al., 2002), the majority of the wild-type CFP hybrid localized to the plasma membrane (Figure 2C). Consistent with the localization of $\mathrm{MRP}_{204-1531}$ observed by immunofluorescence studies, MRP $1_{204-1531}$-CFP was distributed between the plasma membrane and intracellular vesicles (Figure 2C). A graphical representation of differences in subcellular distributions of MRP1-CFP and MRP1 $1_{204-1531}$-CFP was obtained by quantifying the fluorescence profiles (Figure 2C, i and ii) of $x / y$ sections of individual cells and yielded results consistent with those of sucrose density gradient fractionation.

Intracellular MRP1 $204-1531$ Is Glycosylated and Does Not Accumulate in the ER, Golgi, or Lysosomes

ABCC mutant proteins with processing defects have been found to be incompletely N-glycosylated as a result of impaired processing through the Golgi (Sharma et al., 1999; Gentzsch and Riordan, 2001; Fernandez et al., 2002; Gentzsch et al., 2002). Consequently, we used PNGaseF treatment and SDS-PAGE to compare the glycosylation status of MRP1 $1_{204-1531}$ with wild-type MRP1 and a more extensively truncated protein, $M R P 1_{213-1531}$, that we showed previously is retained in the ER (Westlake et al., 2003). Before PNGaseF treatment, all of the MRP1 $1_{204-1531}$ migrated more slowly than $\mathrm{MRP1}_{213-1531}$. After treatment, both truncated proteins comigrated, indicating that the majority of $M R P 1_{204-1531}$ is $N$-glycosylated (Figure 3A). Thus, processing of the truncated protein through the Golgi apparatus seems to be unaffected by lack of MSD0. During the $24-\mathrm{h}$ incubation at $37^{\circ} \mathrm{C}$, we observed some loss of $M R P 1_{204-1531}$ and $\mathrm{MRP}_{213-1531}$ relative to the full-length protein, particularly in the presence of PNGase F, suggesting that under the experimental conditions used both truncated proteins were more susceptible to degradation by low-levels of contaminating proteases.

To further define the subcellular distribution of $\mathrm{MRP}_{204-1531}$ we examined the colocalization of $M R P 1_{204-1531}$ and MRP1 $1_{204-1531}$-CFP with protein markers of different cellular membranes. Neither $\mathrm{MRP1}_{204-1531}$ nor $\mathrm{MRP1}_{204-1531}$-CFP colocalized with the endoplasmic reticulum marker calnexin (Figure 3, B and C) or the Golgi markers NBD $\mathrm{C}_{6}$-ceramide
(Figure 3D) and pAb TGN46 (Figure 3E). Based on these results, we conclude that the intracellular $M R P 1_{204-1531}$ is located in a post-Golgi compartment.

To determine whether the intracellular $M R P 1_{204-1531}$ and MRP $1_{204-1531}$-CFP proteins might be in lysosomal membranes, we stained cells with the lysosomal marker Lamp-2. Very little colocalization with MSD0-less MRP1 was observed (Figure 3, F and G). Consistent with this observation, no evidence of increased degradation of $M R P 1_{204-1531}$ was detected on immunoblots of isolated HEK cell membrane fractions (Figure 2B). Together, these results suggest that removal of MSD0 does not affect processing of MRP1 in the ER or sorting in the Golgi, nor does it increase targeting to lysosomes. Furthermore, MRP1-CFP and the MRP1 ${ }_{204-1531^{-}}$ CFP fusion proteins seem to have subcellular distributions and expression levels (Supplementary Data Figure 1B) very similar to the parental proteins indicating that addition of the CFP "tag" did not detectably alter protein processing or trafficking.

\section{MRP1 $1_{204-1531}$-CFP Colocalizes with Internalized Transferrin}

To determine whether removal of MSD0 increased accumulation in endosomes, live cell internalization assays were performed with Alexa594-labeled transferrin and HEK stable transfectants. Within $30 \mathrm{~min}$ of addition of the fluorescent-labeled ligand, MRP1 $1_{204-1531}-\mathrm{CFP}$ and Alexa594-labeled transferrin colocalized extensively in intracellular vesicles, as well as vesicles contacting the plasma membrane (Figure 4). In some cases, transferrin was detected in large vesicles surrounded by membrane that contained $M R P 1_{204-1531^{-}}$ CFP. In contrast, the only colocalization observed with MRP1-CFP involved regions of the plasma membrane. Thus, the absence of MSD0 seems to cause the accumulation of MRP1 $1_{204-1531}$ in endosomal vesicles as a result of increased internalization from, or decreased recycling to, the plasma membrane.

\section{MSD0 Rescues Plasma Membrane Localization of MRP1 $1_{204-1531}$-YFP}

During the course of these studies, we constructed wild-type and MSD0-less MRP1 YFP fusion proteins. Unexpectedly, MRP1 $1_{204-1531}$-YFP displayed a localization pattern different from the comparable CFP construct. Although MRP1-YFP trafficked normally and was fully active (Supplementary Data Figure 2, A-C), MRP1 $1_{204-1531}$-YFP accumulated in 
large vesicular-like structures (Figure 5A). Why the behavior of this construct differs from the parental protein, or an otherwise identical CFP fusion protein, is presently not known. However, given that the trafficking of MRP1-YFP was normal, the results suggested that the lack of MSD0 contributed to the mislocalization of $\mathrm{MRP}_{204-1531}$-YFP. Consequently, we investigated whether coexpression with MSD0 could rescue the trafficking defect.

We fused the $\mathrm{COOH}$ terminus of $\mathrm{MRP} 1_{1-203}$ to YFP and CFP and stably expressed both fusion proteins in HEK293 cells. Their distribution patterns were indistinguishable, and typical results are illustrated in Figure $5 \mathrm{~B}$ for the $\mathrm{MRP}_{1-203^{-}}$ YFP fusion. The majority of both fusion proteins localized in or near the plasma membrane. Because the presence of a $\sim 27-\mathrm{kDa} \mathrm{COOH}$-terminal CFP tag on $\mathrm{MRP}_{1-203}$ had the potential to impede interactions between MSD0 and the remainder of the protein, we compared the ability of both untagged $\mathrm{MRP}_{1-203}$ and $\mathrm{MRP} 1_{1-203}-\mathrm{CFP}$ to rescue trafficking of $M R P 1_{204-1531}-$ YFP. Both MRP1 $1_{1-203}$ (Figure 5C) and $\mathrm{MRP}_{1-203}$-CFP (Figure 5D) restored plasma membrane localization to $M R P 1_{204-1531}-\mathrm{YFP}$. With the dual expressed MRP1 $1_{1-203}$-CFP and MRP1 $1_{204-1531}$-YFP fragments, strong plasma membrane colocalization could readily be demonstrated. We also investigated whether $M R P 1_{1-203}-\mathrm{CFP}$ could increase the proportion of "untagged" $\mathrm{MRP}_{204-1531}$ that was present on the plasma membrane. Dual expression of the two fragments resulted in a distribution pattern for MRP1 $1_{204-1531}$ very similar to that of full-length protein (Figure $5 \mathrm{E})$.

Trafficking of MRP1 Proteins with Modified $\mathrm{COOH}-$ terminal Regions in the Presence and Absence of MSD0

That MSD0 and MRP1 $1_{204-1531}$ can traffic independently to the plasma membrane suggests that processing and traffick- ing signals must be present in both protein fragments. To confirm this, we sought to identify MRP1 mutant proteins that displayed MSD0-dependent targeting to the plasma membrane. The results obtained with $M R P 1_{204-1531}$-YFP suggested that elements that contributed to targeting of the MRP1 core to the plasma membrane might be located in the $\mathrm{COOH}$-terminal region of the protein. However, we found recently that up to 30 amino acids could be removed from the $\mathrm{COOH}$ terminus of full-length MRP1 without affecting trafficking, despite the fact that removal of only four amino acids was sufficient to markedly decrease transport activity (Westlake et al., 2004). As observed previously, subcellular localization of $\mathrm{MRP}_{1-1501}$ and $\mathrm{MRP}_{1-1527}$ was indistinguishable from that of the full-length protein (Figure 6, A and B). In contrast, proteins lacking MSD0, as well as the $\mathrm{COOH}$-terminal four or 30 amino acids, failed to exit the ER (Figure 6, C and D). We also have shown that a double Ala substitution of the highly conserved dileucine motif in the COOH-terminal region of MRP1, Leu ${ }^{1514-1515}$ has no effect on trafficking of the full-length protein (Westlake et al., 2004). However, in the absence of MSD0, this mutation resulted in extensive colocalization of the MRP1 core with ER marker calnexin (Figure 6E), whereas more conservative substitution of the dileucine motif with Val or Ile did not (Figure 6F and Supplementary Data Figure 3A). Having established that MSD0 enables the processing and plasma membrane trafficking of $\mathrm{COOH}$-terminal MRP1 variants when present as part of the same polypeptide, we determined whether dual expression of $\mathrm{MRP1}_{1-203}$-CFP with MSD0-less COOHterminally truncated or mutated proteins also was effective. $\mathrm{MRP}_{1-203}-\mathrm{CFP}$ restored plasma membrane localization both to MRP1 $1_{204-1501}, M R P 1_{204-1527}$ and the double Leu to Ala mutation, MRP1 $1_{204-1531}$ L1514A-L1515A, with resultant colocalization of the two fragments (Figure 7).

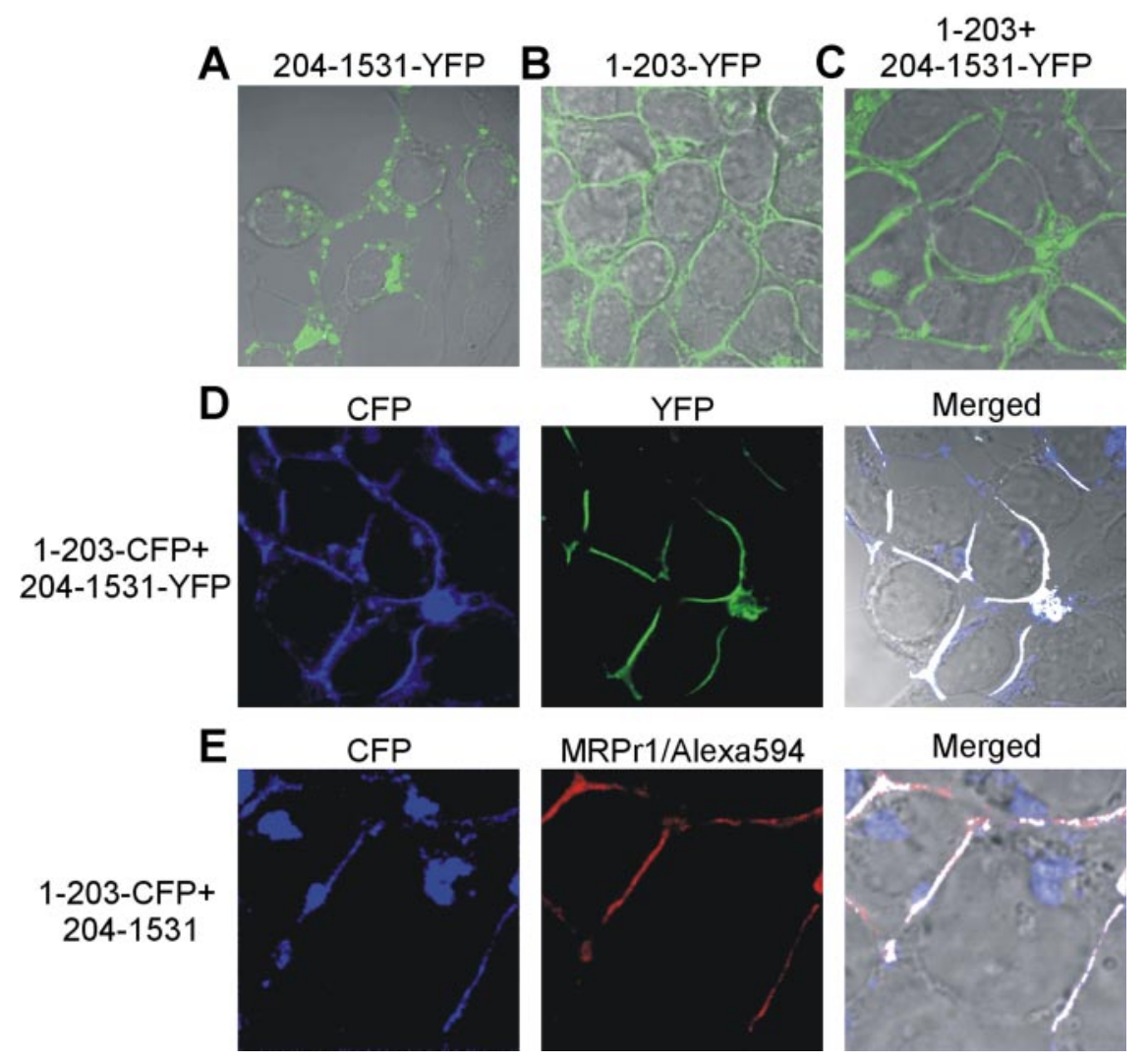

Figure 5. MSD0 trafficking and rescue of non-plasma membrane-targeted mutant MRP1 proteins. (A-C) Merged fluorescent and differential interference contrast (DIC) images of HEK293 cells stably expressing MRP1 $1_{204-1531}-$ YFP and MRP1 $1_{1-203}$-YFP and coexpressing $\mathrm{MRP}_{1-203}$ and $\mathrm{MRP} 1_{204-1531}$ YFP. (D and E) MRP1 $1_{1-203}-\mathrm{CFP}$ (blue signal) coexpressed with MRP1 $204-1531$-YFP (D) and $\mathrm{MRP1}_{204-1531}$ (E, red signal) in HEK293 cells. MRP1 $1_{204-1531}$ was detected as described in Figure 3. YFP is pseudocolored green. Areas of colocalization between the MRP1 fragments are represented in white in the merged fluorescence DIC image. 
A

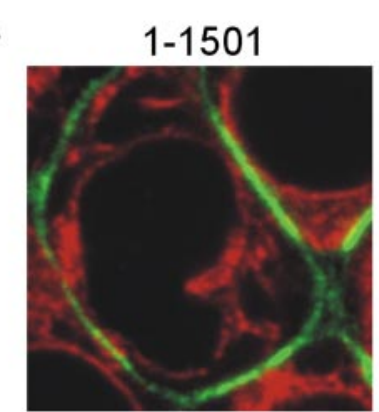

C

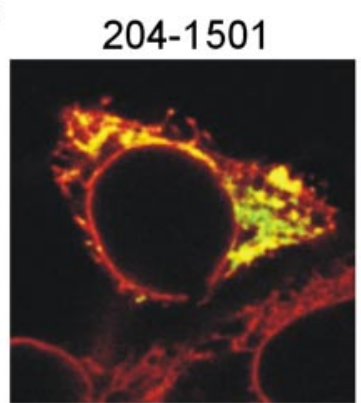

E

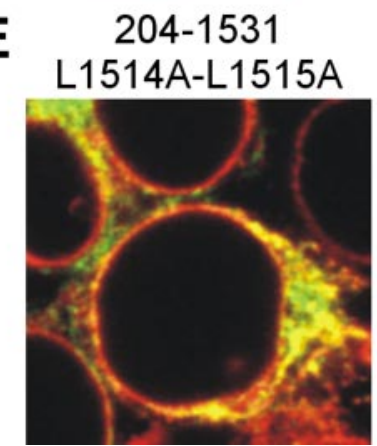

B

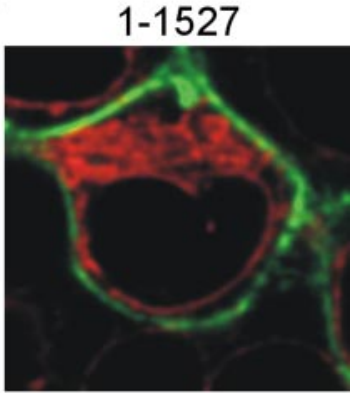

D

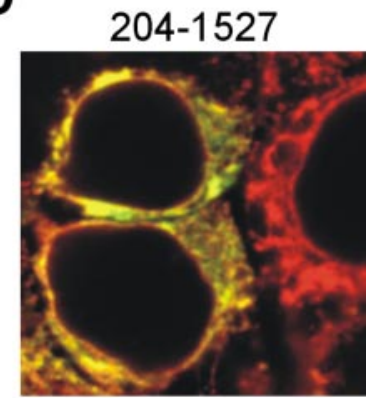

$\mathbf{F}$

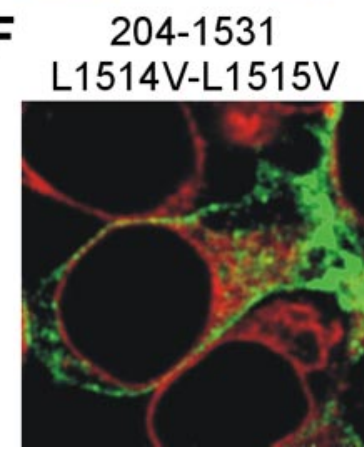

Figure 6. Regulation of MRP1 processing and trafficking by the $\mathrm{NH}_{2}$ - and $\mathrm{COOH}$-terminal regions. (A-F) MSD0-less $\mathrm{COOH}$-terminal truncated/mutated MRP1 proteins were stably expressed in HEK293 cells as described in Materials and Methods. Cells were stained with mAb MRP1r1 and Alexa594 goat anti-rat (pseudocolored green signal) and the mAb anti-calnexin and Alexa488 goat anti-rabbit (pseudocolored red signal). Yellow signals indicate areas of colocalization between the mutant MRP1 proteins and calnexin.

\section{Processing and Trafficking of MRP1 Hybrid Proteins}

Recently, it has been shown that the $\mathrm{COOH}$-terminal region following the Walker B motif in NBD2 of MRP1 can be exchanged for the analogous domain from MRP2 without affecting activity or plasma membrane localization (Konno et al., 2003; Westlake et al., 2004). Consequently, we determined whether this was also true in the absence of MSD0. The $\mathrm{MRP}_{204-1465} / \mathrm{MRP}_{1473-1545}$ hybrid displayed a subcellular distribution similar to that of $\mathrm{MRP}_{204-1531}$ (Figure 8A). Thus, the $\mathrm{COOH}$-terminal region of MRP2 can indeed substitute for the native region of MRP1, even in the absence of MSD0. It also has been reported that the apical location of MRP2 is unaffected by exchange of MSD0 and part of CL3 for the analogous region from MRP1 (Konno et al., 2003). Consistent with this finding, we confirmed that $\mathrm{MRP1}_{1-203}$ / MRP2 ${ }_{189-1545}$ localized to apical membranes in the polarized MDCK-I cells used for this study (Supplementary Data Figure $3 \mathrm{~B})$. Furthermore, we determined that the reciprocal

1-203-CFP+204-1501
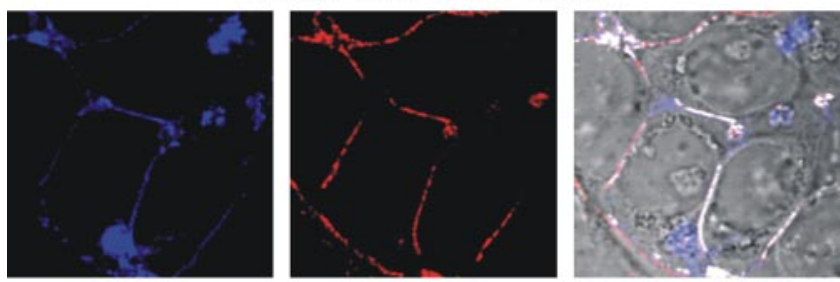

1-203-CFP+204-1527
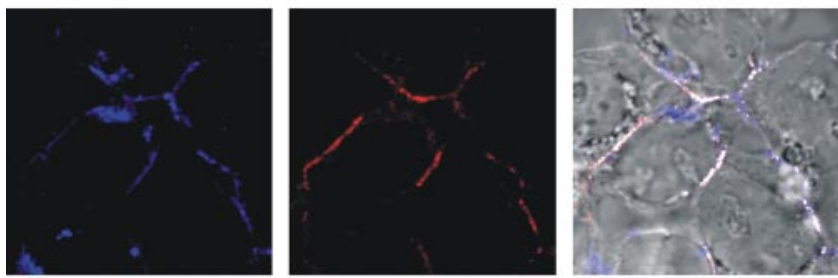

1-203-CFP+204-1531 L1514A-L1515A
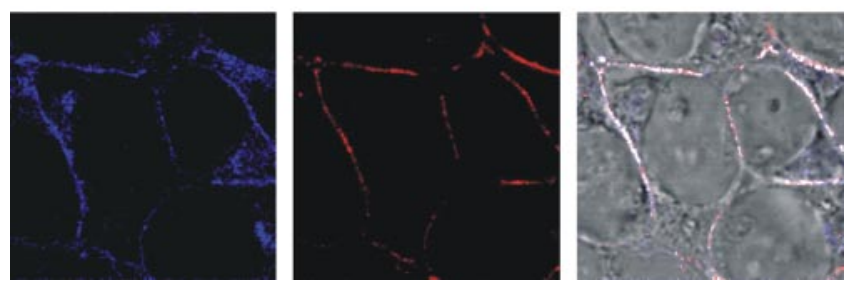

Figure 7. $M R P 1_{1-203}-\mathrm{CFP}$ rescues the processing/trafficking defect of $\mathrm{NH}_{2}$ - and $\mathrm{COOH}$-terminally truncated/mutated MRP1 proteins. Confocal micrographs of HEK293 cells coexpressing MRP1 $1_{1-203}-\mathrm{CFP}$ (blue signal) and core MRP1 variant proteins (red signals) immunodetected as described in Figure 3. Areas of colocalization between the MRP1 fragments are represented in white in the merged fluorescence differential interference contrast images.

MSD0 chimeric protein MRP2 $2_{1-187} / \mathrm{MRP}_{203-1531}$, as well as the MRP3/MRP1 hybrid protein $\mathrm{MRP}_{1-201} / \mathrm{MRP1}_{204-1531}$, localized to basolateral membranes in MDCK-I cells and trafficked to the cell surface in HEK293 cells (Figure 8, B-E). These observations suggest that MSD0 does not contain protein specific processing or trafficking signals. However, given the potential redundancy of trafficking signals present in both MSD0 and the COOH-terminal regions of MRP1 and MRP2, we determined the consequences of exchanging MSD0 in the presence of a $\mathrm{COOH}$-terminal truncation. In contrast to the results obtained with chimeric proteins with an intact $\mathrm{MRP} 1 \mathrm{COOH}$ terminus, $\mathrm{MRP}_{1-187} / \mathrm{MRP}_{203-1501}$ and $\mathrm{MRP}_{1-201} / \mathrm{MRP}_{204-1501}$ were detected intracellularly (Figure 8, F and G) and colocalized with the ER marker calnexin (Supplementary Data Figure 3A). Thus, despite the ability to exchange $\mathrm{COOH}$-terminal regions of MRP1 and MRP2 in the absence of MSD0, neither the $\mathrm{NH}_{2}$-terminal MSD from MRP2 or MRP3 was capable of substituting for MRP1 MSD0 when the COOH-terminal region of the protein was truncated.

\section{DISCUSSION}

Sequence conservation of MSD0 among ABCC proteins is considerably lower than that of either core MSDs (Tusnady et al., 1997; Gao et al., 1998). Alignments of intraspecies homologues and distantly related orthologues reveal little evidence of conserved primary structures suggestive of a 

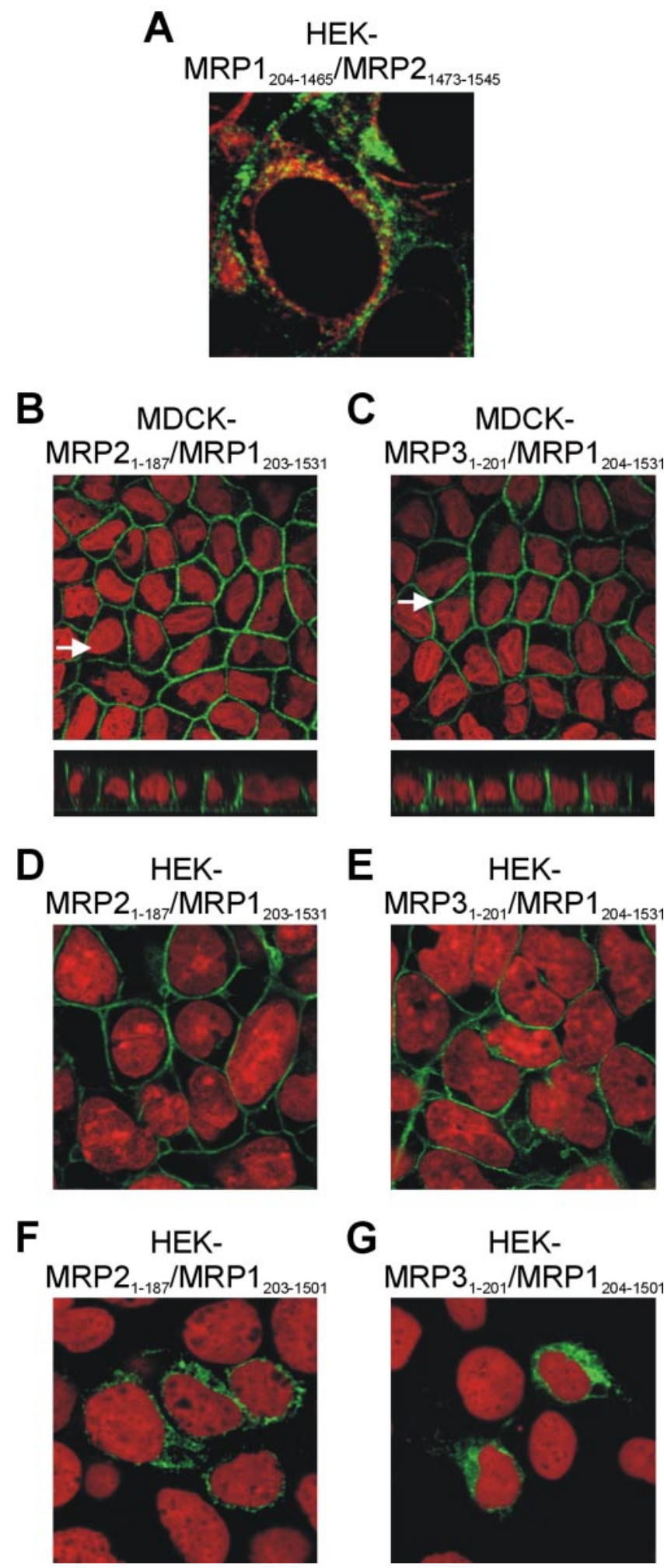

Figure 8. Subcellular localization of $\mathrm{MRP}_{204-1465} / \mathrm{MRP}_{1473-1545}$ and MRP2/MRP1 and MRP3/MRP1 MSD0 hybrid proteins. (A) $\mathrm{MRP}_{204-1465} / \mathrm{MRP}_{1473-1545}$ was stably expressed in HEK293 cells and detected (green signal) along with calnexin (red signal) as described in Figure 6. (B-E) $\mathrm{MRP}_{1-187} / \mathrm{MRP1}_{203-1531}$ and $\mathrm{MRP}_{1-201} / \mathrm{MRP}_{204-1531}$ stably expressed in polarized MDCK-I cells (B and C) and nonpolarized HEK293 cells (D and E). The MDCK-I cells were fixed with $2 \%$ paraformaldehyde and immunodetected with mAb QCRL-1 and Alexa488 goat anti-mouse (green signal), whereas the HEK293 cells were common function. Those limited elements identified, such as the cluster of basic amino acids in CL1 and conserved aromatic and Pro residues (Figure 9), seem likely to contribute to determining the orientation and positions of TMs such as TM1 and TM4, respectively (Ito et al., 2003; Koike et al., 2004). Furthermore, conserved tryptophans in MSD0 have been mutated singly, without affecting the transport activity of the protein (Koike et al., 2002). Nevertheless, studies of three ABCC proteins, SUR1A, MRP2, and Ycf1, indicate that MSD0 has at least a partially conserved role in protein trafficking (Fernandez et al., 2002; Mason and Michaelis, 2002; Babenko and Bryan, 2003). Thus, MRP1, which retains activity and the ability to traffic to the plasma membrane in the absence of MSD0, seems to be the exception (Bakos et al., 1998; Westlake et al., 2003).

Our studies indicate that although MSD0 is not essential for the remainder of MRP1 to traffic to the plasma membrane, its absence does affect the subcellular distribution of the protein. To establish whether this effect was a function of cell type or the ability to traffic specifically to basolateral membranes, we examined the subcellular distribution of MRP1 lacking MSD0 in several polarized and nonpolarized cell lines. These studies consistently indicated that in the absence of MSD0, $<50 \%$ of the protein was present in the plasma membrane compared with $\sim 80 \%$ of intact MRP1, regardless of whether the cell was polarized (Figures 1 and 2).

Subcellular colocalization and deglycosylation studies indicated that the intracellular MSD0-less protein was not present in ER, Golgi, or lysosomal membranes and that the protein had been processed through the Golgi (Figure 3). Consequently, we determined whether the truncated protein was accumulating in endosomes. Video confocal microscopy revealed that transferrin rapidly accumulated in cytoplasmic MRP1 $1_{204-1531}-\mathrm{CFP}$-positive structures (Figure 4). In contrast, colocalization of full-length MRP1-CFP with transferrin was restricted to the cell surface (Figure 4). These results strongly suggest that MSD0 stabilizes retention of MRP1 in the plasma membrane. We cannot completely exclude the possibility that recycling of $M R P 1_{204-1531}$ from endosomes to the plasma membrane also may be impaired or that some $M R P 1_{204-1531}$ may be transported from the trans-Golgi network (TGN) directly to endosomes. However, $\sim 45 \%$ of the MSD0-less protein can be detected on the cell surface, suggesting that direct trafficking to an endosomal fraction is unlikely. Although the mechanism of MRP1 turnover at the plasma membrane is not known, defects in recycling of the wild-type protein have been observed in cisplatin-selected cell lines (Liang et al., 2003). The accumulation of MRP1, MRP2, and the yeast Ycf1 in endosomes in the absence of MSD0, coupled with the observation that appropriate membrane localization of $\mathrm{NH}_{2}$-terminal truncations of these proteins can be restored by coexpression with their respective MSD0, is consistent with a conserved function for this domain in membrane targeting (Figure 5, C-E) (Fernandez et al., 2002; Mason and Michaelis, 2002). When expressed alone, a hemagglutinin-tagged MRP2 MSD0 fragment could not be detected by confocal microscopy (Fernandez et al., 2002). Consequently, its subcellular distribution

Figure 8 (cont). fixed with ethanol and stained with $\mathrm{mAb}$ MRPr1 and Alexa488 goat anti-rat (green signal). Arrows in B and C mark the position of the vertical $x / z$ sections made through the MDCK-I cells shown in the bottom panels. (F and G) Expression and detection of $\mathrm{MRP}_{1-187} / \mathrm{MRP}_{203-1501}$ and $\mathrm{MRP}_{1-201} / \mathrm{MRP}_{204-1501}$ in HEK293 cells as described in D and E. Nuclei were counterstained with propidium iodide (red signal, $B-G$ ). 
Figure 9. Selected regions of MRP1 MSD0 and homologous domains from related $\mathrm{ABC}$ proteins. ClustalW alignment of ABC proteins with an $\mathrm{NH}_{2}$-terminal MSD extension. Identical residues present in all orthologues / homologues are bolded, and conserved domains are highlighted in gray. A charged (residues in white) domain is highlighted in black. EC, extracellular $\mathrm{NH}_{2}$-terminus; TM, transmembrane helix.

\begin{tabular}{|c|c|c|c|}
\hline MRPl topolo & TM1 & CLl & TM4 \\
\hline and sequence & $\hbar \hat{x}$ & $\hat{\imath}$ & \\
\hline Human MRP1/ABCC1 & ...FTKCEQNTVLVWVPCFYLW. & & ALV. \\
\hline Human MRP2/ABCC2 & ... LPLCFEQTVLVWI PLGFLW . & $\mathrm{YK}$ & . FWI \\
\hline Human MRP3/ABCC3 & $\ldots$ LTPCEQNSLLAWVPRI & RHHCR & . FWF \\
\hline Human MRP $6 / \mathrm{ABCC} 6$ & . LSLCFLRTAGVWVPPM & HH & . YWLL \\
\hline Human SUR1A/ABCC 8 & ...NNGCFVDALNVVPHVFLLE. & $\mathrm{VH} \perp \mathrm{HH}$ & . YWTL \\
\hline Anopheles gambiae Mrp & ... LTPCFQQTVLVWAPCAFLW. & LRP & FWFI \\
\hline Drosophila melanogaster Mrp & ... FTPCFEQTALVWTPCAFYW. & & . FWELLTV \\
\hline Danio rerio Mrp2 & VLVWLPLAFLW . & & . FWLLQVV. \\
\hline Raja erinacea Mrp2 & ... LTVCFEQTVLVWVPL & AI & . FWLLSAA. \\
\hline Caenorhabditis elegans Mrp2 & ...VTNCGQHTDFSTIPTLELV. & YK & . YWLLVVV \\
\hline Caenorhabditis elegans Mrp4 & ... LSQCYQHTTLVWFPTAIVE. & IFYRR & SWLVETI. \\
\hline Dictyostelium discoideum Mrp8 & ... FSKCFEDSVVMTLP. & YLEN & . YWVFAEF. \\
\hline Saccharomyces cerevisiae Ycfl & ...FTQCEIDGVILNLS. & $\mathrm{KH}$ & ... YWLEETE. \\
\hline Giberella zeae MRP & ...FTPCFIDVWIASVSVFGLL. & PF & . . YWLFLLI. \\
\hline Arabidopsis thaliana Mrp9 & ...-SLCLKERISIAMQVTFLA. & IRNRGS & ...WWLCSFI. \\
\hline Zea mays Mrp1 & $\ldots{ }^{--K C V Q R T L I D C V N V V L E I}$ & RRRQF & WWVLLSL \\
\hline Triticum aestium Mrp2 & ...-LPCLFLHGASAGAHLILA & & ..WWALELL. \\
\hline
\end{tabular}

could not be determined. However, we found that the corresponding MRP1 fragment fused to YFP or CFP was readily detectable and that the majority of it was present at the cell surface (Figure 5B). Thus, MRP1 MSD0 must contain elements required for proper folding, exit from the ER, and routing to, and retention in, the plasma membrane. That both MRP1 $1_{1-203}$ and MRP1 $1_{204-1531}$ can traffic independently to the plasma membrane indicates that there is likely to be at least partial redundancy between processing and trafficking signals in MSD0 and the core region of the protein. Our results suggest that some of these core elements are located in the COOH-terminal region of MRP1.

Recently, we demonstrated that plasma membrane trafficking of MRP1 was unaffected by removal of the COOHterminal 30 amino acids, whereas elimination of an additional three amino acids, which encroaches on a conserved hydrophobic, four-amino acid motif, results in retention in the ER (Westlake et al., 2003). In contrast, processing and trafficking of SUR1A and MRP2 is impaired after removal of only the COOH-terminal seven and 15 amino acids, respectively (Sharma et al., 1999; Nies et al., 2002). The different effects of $\mathrm{COOH}$-terminal truncation of MRP1 and MRP2 was unexpected because substitution of $\mathrm{COOH}$-terminal region of MRP1 with that of MRP2 had no effect on trafficking (Konno et al., 2003; Westlake et al., 2004), even in the absence of MSD0 (Figure 8A), suggesting a high level of functional conservation between the $\mathrm{COOH}$-terminal regions of the two MRPs.

MRP1, MRP2, CFTR, and SUR1A contain several highly conserved amino acids in their $\mathrm{COOH}$-terminal regions (Westlake et al., 2004). Mutation of one of these residues (Phe ${ }^{1574}$ ) in SUR1A decreases surface expression of the protein and increases retention in the ER (Sharma et al., 1999). These proteins also contain a conserved dileucine motif that is important for SUR1A plasma membrane targeting (Sharma et al., 1999). Dileucine motifs in numerous proteins have been shown to function as endosomal sorting and/or ER exit signals (Bonifacino and Glick, 2004). However, in MRP1 elimination of the $\mathrm{COOH}$-terminal region containing the conserved dileucine and Phe residue had no effect on protein trafficking but markedly decreased the activity of the protein (Westlake et al., 2004). The disparity between the apparent role of these conserved motifs prompted us to examine whether the presence of MSD0 might mask the existence of processing or trafficking signals in the $\mathrm{COOH}$ terminal region of MRP1.

We found that $\mathrm{COOH}$-terminal truncations of MRP1 that did not affect trafficking of the protein in the presence of MSD0 resulted in almost complete retention in the ER in its absence (Figure 6, C and D). Mutation of the dileucine motif to Ala had a similar effect (Figure 6E), whereas substitution with Ile (Supplementary Data Figure 3A) or Val (Figure 6F), which occur naturally at comparable locations in other $A B C$ proteins, resulted in a distribution very similar to that of the parental MSD0-less protein. Although this suggests that the $\mathrm{COOH}$-terminal region of MRP1 may contain functional ER exit signals, at present, we cannot exclude the possibility that that the $\mathrm{COOH}$-terminal mutations result in structural alterations that are only detected by the ER quality control system in the absence of MSD0. However, because coexpression with the $M R P 1_{1-203}-\mathrm{CFP}$ fusion protein restored the ability of the $\mathrm{COOH}$-terminal truncated or mutated protein to traffic to the plasma membrane (Figure 7), it is clear that the coexpressed MSD0 must associate with the core of the protein in the ER.

The $\mathrm{NH}_{2}$-terminal MSDs of MRP1, MRP2, and MRP3 all contain possible ER sorting signals, including multiple dileucine motifs or variants thereof. Although MSD0 of MRP2 and MRP3 can substitute for MRP1 MSD0 when the $\mathrm{COOH}$ terminus of the protein is intact (Konno et al., 2003) (Figure 8, B-E), they cannot do so when the $\mathrm{COOH}$-terminal region of the protein is truncated (Figure $8, F$ and $G$ ). Thus, it is possible that MSD0 of MRP1 contains an anterograde trafficking signal that the other two domains lack. Alternatively, only MRP1 MSD0 may be able to establish interactions necessary for the COOH-terminally truncated or mutated proteins to exit the ER. Whether these interactions are exclusively with the core of MRP1 or involve another protein, as shown for the SURs (Babenko and Bryan, 2003; Chan et al., 2003), is under investigation.

\section{ACKNOWLEDGMENTS}

The $\mathrm{pAb}$ antibody to TGN46 was a gift from Dr. Ponnambalam (University of Leeds). This work was supported by a grant from the National Cancer Institute of Canada with funds from the Terry Fox Run. C.J.W. is the recipient of an Ontario Graduate Scholarship S.P.C.C. is the Canada Research Chair in Cancer Biology, and R.G.D. is the Stauffer Professor of Basic Oncology at Queen's University.

\section{REFERENCES}

Babenko, A. P., and Bryan, J. (2003). Sur domains that associate with and gate KATP pores define a novel gatekeeper. J. Biol. Chem. 278, 41577-41580.

Bakos, E., et al. (1998). Functional multidrug resistance protein (MRP1) lacking the N-terminal transmembrane domain. J. Biol. Chem. 273, 32167-32175.

Bates, S. E. (2003). Solving the problem of multidrug resistance: ABC transporters in clinical oncology. In: ABC Proteins: From Bacteria to Man, ed. I. B. 
Holland, S.P.C. Cole, K. Kuchler, and C. F. Higgins, New York: Elsevier Science, 359-391.

Bonifacino, J. S., and Glick, B. S. (2004). The mechanisms of vesicle budding and fusion. Cell 116, 153-166.

Chan, K. W., Zhang, H., and Logothetis, D. E. (2003). N-terminal transmembrane domain of the SUR controls trafficking and gating of Kir6 channel subunits. EMBO J. 22, 3833-3843.

Deeley, R. G., and Cole, S. P. (2003). Multidrug resistance protein 1 (ABCC1). In: ABC Proteins: From Bacteria to Man, ed. I. B. Holland, S.P.C. Cole, K. Kuchler, and C. F. Higgins, New York: Elsevier Science, 393-422.

Fernandez, S. B., Hollo, Z., Kern, A., Bakos, E., Fischer, P. A., Borst, P., and Evers, R. (2002). Role of the N-terminal transmembrane region of the multidrug resistance protein MRP2 in routing to the apical membrane in MDCKII cells. J. Biol. Chem. 277, 31048-31055.

Gao, M., Loe, D. W., Grant, C. E., Cole, S. P., and Deeley, R. G. (1996) Reconstitution of ATP-dependent leukotriene $\mathrm{C}_{4}$ transport by Co-expression of both half-molecules of human multidrug resistance protein in insect cells. J. Biol. Chem. 271, 27782-27787.

Gao, M., Yamazaki, M., Loe, D. W., Westlake, C. J., Grant, C.E., Cole, S. P., and Deeley, R. G. (1998). Multidrug resistance protein. Identification of regions required for active transport of leukotriene $\mathrm{C}_{4}$. J. Biol. Chem. 273, 1073310740

Gentzsch, M., Aleksandrov, A., Aleksandrov, L., and Riordan, J. R. (2002). Functional analysis of the C-terminal boundary of the second nucleotide binding domain of the cystic fibrosis transmembrane conductance regulator and structural implications. Biochem. J. 366, 541-548.

Gentzsch, M., and Riordan, J. R. (2001). Localization of sequences within the C-terminal domain of the cystic fibrosis transmembrane conductance regulator which impact maturation and stability. J. Biol. Chem. 276, 1291-1298.

Grant, C. E., Kurz, E. U., Cole, S. P., and Deeley, R. G. (1997). Analysis of the intron-exon organization of the human multidrug-resistance protein gene (MRP) and alternative splicing of its mRNA. Genomics 45, 368-378.

Grant, C. E., Valdimarsson, G., Hipfner, D. R., Almquist, K. C., Cole, S. P., and Deeley, R. G. (1994). Overexpression of multidrug resistance-associated protein (MRP) increases resistance to natural product drugs. Cancer Res. 54, $357-361$.

Haimeur, A., Conseil, G., Deeley, R. G., and Cole, S. P. (2004). The MRPrelated and BCRP/ABCG2 multidrug resistance proteins: biology, substrate specificity and regulation. Curr. Drug Metab. 5, 21-53.

Haimeur, A., Deeley, R. G., and Cole, S. P. (2002). Charged amino acids in the sixth transmembrane helix of multidrug resistance protein 1 (MRP1/ABCC1) are critical determinants of transport activity. J. Biol. Chem. 277, 41326-41333.

Higgins, C. F. (2001). ABC transporters: physiology, structure and mechanism-an overview. Res. Microbiol. 152, 205-210.

Hipfner, D. R., Almquist, K. C., Leslie, E. M., Gerlach, J. H., Grant, C. E., Deeley, R. G., and Cole, S. P. (1997). Membrane topology of the multidrug resistance protein (MRP). A study of glycosylation-site mutants reveals an extracytosolic $\mathrm{NH}_{2}$ terminus. J. Biol. Chem. 272, 23623-23630.

Ito, K., Oleschuk, C. J., Westlake, C., Vasa, M. Z., Deeley, R. G., and Cole, S. P. (2001a). Mutation of Trp1254 in the multispecific organic anion transporter multidrug resistance protein 2 (MRP2) (ABCC2), alters substrate specificity and results in loss of methotrexate transport activity. J. Biol. Chem. 276, 38108-38114.

Ito, K., Olsen, S. L., Qiu, W., Deeley, R. G., and Cole, S. P. (2001b). Mutation of a single conserved tryptophan in multidrug resistance protein 1 (MRP1/ $\mathrm{ABCC} 1$ ) results in loss of drug resistance and selective loss of organic anion transport. J. Biol. Chem. 276, 15616-15624.

Ito, K., Weigl, K. E., Deeley, R. G., and Cole, S. P. (2003). Mutation of proline residues in the $\mathrm{NH}(2)$-terminal region of the multidrug resistance protein MRP1 (ABCC1): effects on protein expression, membrane localization, and transport function. Biochim. Biophys. Acta 1615, 103-114.

Kast, C., and Gros, P. (1997). Topology mapping of the amino-terminal half of multidrug resistance-associated protein by epitope insertion and immuno fluorescence. J. Biol. Chem. 272, 26479-26487.

Koike, K., Conseil, G., Leslie, E. M., Deeley, R. G., and Cole, S. P. (2004) Identification of proline residues in the core cytoplasmic and transmembrane regions of multidrug resistance protein 1 (MRP1/ABCC1) important for transport function, substrate specificity, and nucleotide interactions. J. Biol. Chem. 279, 12325-12336.
Koike, K., Oleschuk, C. J., Haimeur, A., Olsen, S. L., Deeley, R. G., and Cole, S. P. (2002). Multiple membrane-associated tryptophan residues contribute to the transport activity and substrate specificity of the human multidrug resistance protein, MRP1. J. Biol. Chem. 277, 49495-49503.

Konno, T., Ebihara, T., Hisaeda, K., Uchiumi, T., Nakamura, T., Shirakusa, T., Kuwano, M., and Wada, M. (2003). Identification of domains participating in the substrate specificity and subcellular localization of the multidrug resistance proteins MRP1 and MRP2. J. Biol. Chem. 278, 22908-22917.

Leslie, E. M., Ito, K., Upadhyaya, P., Hecht, S. S., Deeley, R. G., and Cole, S. P. (2001). Transport of the $\beta$-O-glucuronide conjugate of the tobacco-specific carcinogen 4-(methylnitrosamino)-1-(3-pyridyl)-1-butanol (NNAL) by the multidrug resistance protein 1 (MRP1). Requirement for glutathione or a non-sulfur-containing analog. J. Biol. Chem. 276, 27846-27854

Leslie, E. M., Letourneau, I. J., Deeley, R. G., and Cole, S. P. (2003). Functional and structural consequences of cysteine substitutions in the $\mathrm{NH}(2)$ proximal region of the human multidrug resistance protein 1 (MRP1/ABCC1). Biochemistry $42,5214-5224$

Li, Z. S., Szczypka, M., Lu, Y. P., Thiele, D. J., and Rea, P. A. (1996). The yeast cadmium factor protein (YCF1) is a vacuolar glutathione S-conjugate pump. J. Biol. Chem. 271, 6509-6517.

Liang, X. J., Shen, D. W., Garfield, S., and Gottesman, M. M. (2003). Mislocalization of membrane proteins associated with multidrug resistance in cisplatin-resistant cancer cell lines. Cancer Res. 63, 5909-5916.

Loe, D. W., Almquist, K. C., Deeley, R. G., and Cole, S. P. (1996). Multidrug resistance protein (MRP)-mediated transport of leukotriene $\mathrm{C} 4$ and chemotherapeutic agents in membrane vesicles. Demonstration of glutathione-dependent vincristine transport. J. Biol. Chem. 271, 9675-9682.

Loe, D. W., Stewart, R. K., Massey, T. E., Deeley, R. G., and Cole, S. P. (1997). ATP-dependent transport of aflatoxin B1 and its glutathione conjugates by the product of the multidrug resistance protein (MRP) gene. Mol. Pharmacol. 51, 1034-1041.

Mason, D. L., and Michaelis, S. (2002). Requirement of the N-terminal extension for vacuolar trafficking and transport activity of yeast Ycf1p, an ATPbinding cassette transporter. Mol. Biol. Cell 13, 4443-4455.

Nies, A. T., Konig, J., Cui, Y., Brom, M., Spring, H., and Keppler, D. (2002). Structural requirements for the apical sorting of human multidrug resistance protein 2 (ABCC2). Eur. J. Biochem. 269, 1866-1876.

Otonkoski, T., et al. (1999). A point mutation inactivating the sulfonylurea receptor causes the severe form of persistent hyperinsulinemic hypoglycemia of infancy in Finland. Diabetes 48, 408-415.

Qian, Y. M., Qiu, W., Gao, M., Westlake, C. J., Cole, S. P., and Deeley, R. G. (2001a). Characterization of binding of Leukotriene $\mathrm{C}_{4}$ by human multidrug resistance protein 1, Evidence of differential interactions with $\mathrm{NH}_{2}$ - and COOH-proximal halves of the protein. J. Biol. Chem. 276, 38636-38644.

Qian, Y. M., Song, W. C., Cui, H., Cole, S. P., and Deeley, R. G. (2001b). Glutathione stimulates sulfated estrogen transport by multidrug resistance protein 1. J. Biol. Chem. 276, 6404-6411.

Raab-Graham, K. F., Cirilo, L. J., Boettcher, A. A., Radeke, C. M., and Vandenberg, C. A. (1999). Membrane topology of the amino-terminal region of the sulfonylurea receptor. J. Biol. Chem. 274, 29122-29129.

Renes, J., de Vries, E. G., Nienhuis, E. F., Jansen, P. L., and Muller, M. (1999) ATP- and glutathione-dependent transport of chemotherapeutic drugs by the multidrug resistance protein MRP1. Br. J. Pharmacol. 126, 681-688.

Sakamoto, H., Hara, H., Hirano, K., and Adachi, T. (1999). Enhancement of glucuronosyl etoposide transport by glutathione in multidrug resistanceassociated protein-overexpressing cells. Cancer Lett. 135, 113-119.

Sharma, N., Crane, A., Clement, J. P., Gonzalez, G., Babenko, A. P., Bryan, J. and Aguilar-Bryan, L (1999). The C terminus of SUR1 is required for trafficking of KATP channels. J. Biol. Chem. 274, 20628-20632.

Tusnady, G. E., Bakos, E., Varadi, A., and Sarkadi, B. (1997). Membrane topology distinguishes a subfamily of the ATP-binding cassette (ABC) transporters. FEBS Lett. 402, 1-3.

Westlake, C. J., Payen, L., Gao, M., Cole, S. P., and Deeley, R. G. (2004) Identification and characterization of functionally important elements in the multidrug resistance protein $1 \mathrm{COOH}$-terminal region. J. Biol. Chem. 279, 53571-53583.

Westlake, C. J., Qian, Y. M., Gao, M., Vasa, M., Cole, S. P., and Deeley, R. G. (2003). Identification of the structural and functional boundaries of the multidrug resistance protein 1 cytoplasmic loop 3. Biochemistry 42, 14099-14113.

Zhang, D. W., Gu, H. M., Vasa, M., Muredda, M., Cole, S. P., and Deeley, R. G. (2003). Characterization of the role of polar amino acid residues within predicted transmembrane helix 17 in determining the substrate specificity of multidrug resistance protein 3 . Biochemistry 42, 9989-10000. 